\title{
Concrete composites of double structure formation
}

\author{
Yuri Bazhenov ${ }^{1}$, Lev Alimov ${ }^{1, *}$ and Viktor Voronin ${ }^{1}$ \\ ${ }^{1}$ Moscow state university of civil engineering, Yaroslavskoye shosse, 26, Moscow, Russia, 129337
}

\begin{abstract}
Modification of concrete composites includes the manufacture of a concrete product, followed by its impregnation with monomers such as styrene and methyl methacrylate, capable of curing in concrete pores. However, despite the high efficiency of concrete modification with polymers, their production is hampered by the complexity of the technology associated with the toxicity and explosiveness of these impregnating materials. The article proposes to use technical vegetable oil as an impregnating material. The study showed that the treatment of concretes with technical vegetable oil (TVO) reduces their water absorption to less than $1 \%$, strength by $40 \%$, and frost resistance by an order of magnitude.
\end{abstract}

\section{Introduction}

Modified concrete composites are materials pores of which are filled with polymers such as styrene, methyl methacrylate with their subsequent polymerization directly into concrete pores $[1,2,3]$. Because of sealing the material structure with the polymer, and the effect of a number of physicochemical factors, its strength increases by several times, and frost resistance and resistance significantly increases in aggressive media [4-7].

However, despite the high efficiency of concrete composite modification by polymers, their production is hindered by the complexity of the technology associated with toxicity, explosion and fire hazard of impregnating materials $[8,9]$.

In this connection, studies were carried out on the use of technical vegetable oils as technical impregnation compositions, belonging to drying oils, which can significantly simplify the technology [10]. The studies conducted showed that the simplest, most effective, and cheapest impregnating composition is technical vegetable oil (TVO) without any additives, heated to $130-140{ }^{\circ} \mathrm{C}$ and capable of polymerization in the body of concrete $[11,12]$.

The method of concrete modification with technical vegetable oil was developed on the concrete of grade 400, with the following composition: at the consumption rate of cement, water, filler $409,193,1,873 \mathrm{~kg} / \mathrm{m}^{3}$, respectively, having an average density of $2,169 \mathrm{~kg} / \mathrm{m}^{3}$ with hardness of $55 \mathrm{~s}$.

\footnotetext{
Corresponding author: AlimovLA@mgsu.ru
} 


\section{Materials and methods}

Portland cement CEM I 42.5 B GOST 31108-2016, granite crushed stone - with fraction contents of $10-20-10 \%, 5-10-30 \%, 2.5-5-45 \%, 1.25-2,5-9 \%, 0.63-1.25-6 \%$.

Samples were prepared, which after 28 days of normal hardening, were impregnated with TVO. Vacuum treatment was used to accelerate the impregnation process. The oil was heated to $130-140{ }^{\circ} \mathrm{C}$, concrete samples to $200{ }^{\circ} \mathrm{C}$.

When the heated concrete sample is immersed into oil, intensive impregnation occurs. Then concrete gradually cools, the air in the sample is compressed, vacuum is created and oil is drawn into concrete pores. The amount of absorbed monomer is increased by $20-25 \%$ compared to studies without self-vacuuming.

The polymerization of saturated samples, carried out with infrared radiation at a temperature of $150-160{ }^{\circ} \mathrm{C}$ for 2.5 .8 and 24 hours, showed that about $70 \%$ of oil passes into a three-dimensional polymer. At the same time, the strength of the impregnated concrete increased in comparison with the control one, is equal to $42.3 \mathrm{MPa}$, after 2 hours $-19.2 ; 5$ hours - 24; 8 hours - 42.324 hours - 59.2 $\mathrm{MPa}$.

Thus, the strength of the modified sample after this treatment was $40 \%$ higher than the control sample after 24 hours of the polymerization.

\section{Results}

Based on the studies carried out, the following method for modifying concrete with heat treatment was adopted: the manufactured concrete products are dried at temperature of 180$200{ }^{\circ} \mathrm{C}$, oil is heated to $130-140{ }^{\circ} \mathrm{C}$. Then the product is immersed in oil. The impregnation is carried out for as long as it is necessary to penetrate oil to a predetermined depth. The impregnated articles are then polymerized at the temperature of about $200{ }^{\circ} \mathrm{C}$ for $6-8$ hours.

Thus, concretes modified by technical vegetable oils are materials with the double structure formation. They consist of a concrete matrix and are distributed over the volume of the polymeric material network. Both components have continuity and a common interaction surface. Oil, getting polymerized in pores and capillaries of cement stone, forms a three-dimensional network, which reinforces the silicate base. Not all pores can be filled with polymer. Electron-microscopic studies of modified concrete showed that in pores larger than 200-600 $\mu \mathrm{m}$ there is a central zone not filled with oil. Processing of the experimental data showed that the maximum amount of absorbed oil $(\mathrm{O})$, depending on the water absorption of concrete $(\mathrm{W})$ was:

$$
\mathrm{O}=0.8 \mathrm{~W}-21.28, \% \text { in mass }
$$

The dependence of maximum oil absorption upon the concrete porosity $(P)$ was:

$$
\mathrm{O}=0.43 P, \% \text { in volume }
$$

The coefficient of saturation of pores equals $0.4-0.45$, and that of cement stone is 0.5 -0.55 .

To accelerate the assessment of concrete frost resistance, a dilatometric method of structure analysis was used $[13,14,15]$. The measurement procedure for temperaturehumidity deformations is as follows: prior the test, samples of tested concrete, $7 \times 7 \times 21 \mathrm{~cm}$ in size, are saturated with water, insulated with frost-resistant rubber, placed in a dial gauge, and then into the freezer; temperature control is carried out in the chamber and in the sample middle; strain readings are recorded every $5^{\circ} \mathrm{C}$ at the time when the temperature in the chamber and the sample middle is equalized. On the base of obtained data, a graph is plotted (Fig. 1).

The data in Fig. 1 show that the dilatometric curve of a water-saturated sample of a concrete based upon freezing is characterized by presence of anomalous expansion deformations that occur at temperatures of $-5 \ldots-10^{\circ} \mathrm{C}$ and $-40 \ldots-50^{\circ} \mathrm{C}$. However, there 
are no such deformations in modified concretes. This indicates a high frost resistance of modified concrete.
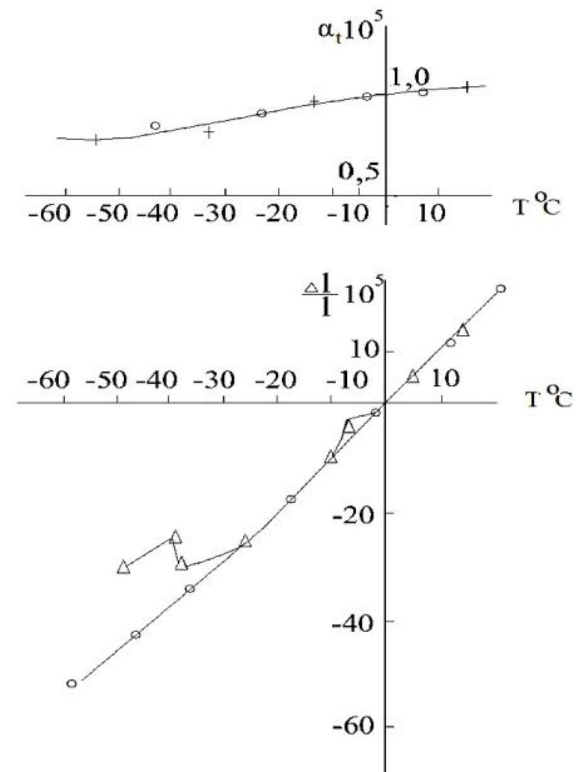

Fig. 1. Dilatometric curve and coefficient of thermal expansion of concrete in temperature range from $+20{ }^{\circ} \mathrm{C}$ up to $-60{ }^{\circ} \mathrm{C}: \Delta$----- $\Delta$ - thermal deformation of concrete foundation; o-----o - temperature deformation of modified concrete.

\section{Conclusions}

To predict properties of fair-faced concrete modified with heat treatment, the mathematical design of the experiment was carried out and polynomial mathematical models of the basic properties were calculated: strength, porosity and the amount of absorbed oil.

For the mathematical design of the experiment, the $D$-optimal plan for the dimension K-3 of the range $\mathrm{B}$ was used. At that, the main independent parameters were adopted:

- Cement consumption (C) - X1;

- binder activity $(\mathrm{R})$ - X2;

- water flow rate $(\mathrm{W})$ - X3

Table 1. Levels and intervals varying factors.

\begin{tabular}{|c|c|c|c|c|c|}
\hline \multicolumn{2}{|c|}{ Description } & \multicolumn{2}{c|}{ Levels varying factors } & $\begin{array}{c}\text { Intervals } \\
\text { varying } \\
\text { factors }\end{array}$ \\
\hline Natural & Code & +1 & 0 & -1 & 250 \\
\hline Cement & $\mathrm{X} 1$ & 740 & 490 & 240 & 100 \\
\hline Strength & $\mathrm{X} 2$ & 600 & 500 & 400 & 85 \\
\hline Water & $\mathrm{X} 3$ & 310 & 225 & 140 & \\
\hline
\end{tabular}

The following polynomial models were obtained:

- strength of modified concrete

$\mathrm{R}=-6.9+0.005 \mathrm{C}+0.29 \mathrm{R}-0.39 \mathrm{~B}-0.000053 \mathrm{C} 2-0.0002 \mathrm{R} 2+0.00035 \mathrm{~B} 2+$ $0.000098 \mathrm{C} \mathrm{R}+0.00024 \mathrm{CI}-0.00016 \mathrm{RV}$

- porosity of modified concrete

$\mathrm{P}=-0.85+0.014 \mathrm{C}+0.0031 \mathrm{R}-0.1 \mathrm{~B}+0.00000035 \mathrm{C} 2-0.00000022 \mathrm{R} 2-0.0000038$

$\mathrm{B} 2+0.0000015 \mathrm{C} \mathrm{R}+0.00000059 \mathrm{C}-0.00000147 \mathrm{RB}$ 
- amount of absorbed oil

$\mathrm{O}=-0.0057-0.0055 \mathrm{C}+0.000028 \mathrm{R}+0.043 \mathrm{~B}-0.0000003 \mathrm{C} 2-0.000004 \mathrm{R} 2-$ $0.0000047 \mathrm{~B} 2+0.0000011 \mathrm{C} \mathrm{R}+0.00000012 \mathrm{CB}-0.0000038 \mathrm{RB}$

The adequacy of all the models was checked by the Fisher's ratio test and showed satisfactory convergence of calculated and experimental data.

Thus, the treatment of concrete with heat treatment reduces their water absorption to less than $1 \%$, increases strength by $40 \%$, and increases frost resistance by an order of magnitude.

\section{References}

1. V. Voronin, PhD Thesis, Moscow State University of Civil Engineering, Russian Federation, (1985)

2. A. Ouskern, A Review of Properties of Polymer impregnated Concrete. «New materials in Concrete Construction.», University of Illinoys Conference. Chicago, 1971

3. E Manuilova, PhD Thesis, Moscow State University of Civil Engineering, Russian Federation, (1995)

4. U. Magdeev, A Davidyuk, B. Sadov, Industry of construction materials of Moscow(in Russian - Promyshlennost stroitelnykh materialov Moskvy), 7(1986)

5. T. Sebök, , O. Stráněl, Cem. and Conc. Res., 34, 10 (2004)

6. O. Larsen, V. Naruts, Mag. of Civ. Eng., 8 (2016)

7. J Chen, D Zampini, , A Walliser, Cem. and Conc. Res., 32, 1(2002)

8. D. Gemert, L. Czarnecki, M. Maultzsch, H. Schorn, A. Beeldens, P. Lukowski, E. Knapen, Cem. and Conc. Comp., 27, 9-10 (2005)

9. Marcelo Amianti, Vagner Roberto Botaro, Cem. and Conc. Comp., 30, 1 (2008)

10. S. Yehia, M. Fawzy, Int. Jour. of Curr. Eng. and Tech., 7, 2 (2017)

11. M. Bhuttaa, T. Maruyab, K Tsurutac, Con. and Build. Mat., 43 (2013)

12. C.- H. Chen, R. Huang, J.K. Wu, Journ. of the Ch. Inst. of Eng., 1 (2007)

13. G. Gondrashov, Eur. J. of Nat. Hist., 5 (2008)

14. M. Amianti, V. Botaro, Cem. and Conc. Comp., 30, 1 (2008)

15. F. Gilabert, K. Van Tittelboom, J. Van Stappen, V. Cnudde, N. De Belieb, W. Van Paepegem, 77 (2017) 